\title{
Correction to: Oxazolidinones and Related Heterocycles as Chiral Auxiliaries/Evans and Post-Evans Auxiliaries
}

\author{
Asmaa Kamal Mourad and Constantin Czekelius
}

\section{Correction to:}

Chapter "Oxazolidinones and Related Heterocycles as Chiral Auxiliaries/Evans and Post-Evans Auxiliaries" in: Asmaa Kamal Mourad and Constantin Czekelius, Top Heterocycl Chem, DOI: 10.1007/7081_2020_36

The original version of this chapter unfortunately contained an error. A part of the presentation of Scheme 56 was missing. The corrected Scheme 56 is given below.

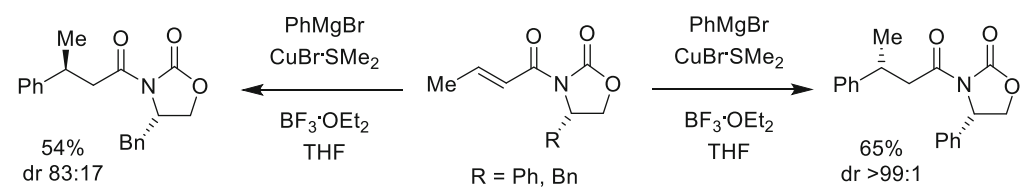

Scheme 56 Diastereoselective addition of cuprates to crotonyl-oxazolidinones

The online version of the chapter can be found at DOI: 10.1007/7081_2020_36 